\title{
THE ANALYSIS OF STAINLESS STEEL WELDED CONNECTIONS MADE BY LOW ENERGY AND CLASSIC WELDING PROCESSES
}

\author{
M. Gucwa*, J. Winczek ${ }^{* *}$, M. Kukuryk ${ }^{* * *}$, K. Makles ${ }^{\dagger}$
}

\begin{abstract}
Welding of stainless steels, and in particular steels with austenitic structure requires proper technical preparation, appropriate technology and technical knowledge. The main area of research of the experimental part of the work was to compare the classical MIG / MAG welding method with its alternative $S T T ®$ variant in terms of weldability, i.e. determine the possible advantages in various aspects of welding (weld quality, economy) thanks to the STT® method. For this purpose, joints were made using both methods for two different grades of stainless steels. Samples were cut from such prepared joints, which were subjected to non-destructive, micro- and macroscopic tests. Practical STT® welding tests confirmed the advantage over the classic GMAW method, however, this advantage applies only to a certain type of weld (root) and a thickness not exceeding $6 \mathrm{~mm}$. This means that cost-effectiveness is only possible in the case of a large number of such welds performed during the working day. In another case, anyway, one must use the second welding source to position the groove-filling layers.
\end{abstract}

Keywords: STT, welding, steel, stainless, structure

\section{Introduction}

The gas metal arc welding (GMAW) method, which is the most popular arc welding process due to a wide range of applications, is not without drawbacks. A large amount of heat input to the material adversely affects the properties of the welded joint and is problematic in welding thin-walled elements (thickness $<2 \mathrm{~mm}$ ) due to thermal deformation. Another issue related to welding is aesthetics - spatter contamination adjacent to the joint surfaces require removal, which is labor-intensive, affects the efficiency and complicates the technological processes accompanying the production. Spatter is accompanied by emissions of gases and dust that negatively affect the working environment. In addition, welding of dissimilar metal joints and joining elements coated with metallic coatings was a big problem. As a result of intensive research, each of the significant producers of welding sources proposed its alternative version of the GMAW method, with low heat input, low spatter and controlled short circuit transfer (Norrish, 2014 and Scotti, 2014). This is how Cold Metal Transfer (CMT) was created by Fronius, ColdArc ${ }^{\circledR}$ by EWM, Surface Tension Transfer (STT) - Lincoln Electric, Regulated Metal Deposition (RMD TM) - Miller, FastROOT - Kemppi, Controlled Short Circuit (CSC TM) MIG - Jetline, Controlled Bridge Transfer (CBT) - Daihen Corp., ColdMIG - Merkle or QSet- ESAB. The common denominator for all these methods is to reduce the total energy input during welding. The low energy course of the welding process also results from the use of a short arc to make the joint using a small diameter welding wire (about 1-1.2 mm). Due to the smaller amount of heat supplied to the joint, these

PhD. Marek Gucwa: Institute of Mechanical Technologies, Czestochowa University of Technology; Dabrowskiego 69; 42201;Czestochowa;Poland; mgucwa@spaw.pcz.pl

** Prof. Jerzy Winczek, PhD.: Institute of Mechanical Technologies, Czestochowa University of Technology; Dabrowskiego 69; 42-201;Czestochowa;Poland; winczek@imipkm.pcz.czest.pl

*** PhD. Marcin Kukuryk: Institute of Mechanical Technologies, Czestochowa University of Technology; Dabrowskiego 69; 42201;Czestochowa;Poland; kukuryk@itm.pcz.pl

$\dagger \quad$ Msc. Krzystof Makles: Institute of Mechanical Technologies, Czestochowa University of Technology; Dabrowskiego 69; 42201;Czestochowa;Poland; krzysztof_makles@interia.eu 
methods seem to be attractive also in the case of combining stainless steels, and in particular steel with austenitic structure. Reducing the amount of heat brought to the joint should have a positive effect on the structure, limiting the size of the heat zone and structural changes such as the amount of $\delta$ ferrite, sigma phase or chromium carbides responsible for corrosion (Gucwa, 2014, Mohammed, 2015). The main purpose of the work was to examine the suitability of the STT® method to create austenitic stainless steel joints and compare it with the classical GMAW method.

\section{Methods}

X2CrNi18-9 steel with austenitic structure was selected for welding tests. All steel plates with dimensions 300x 150x $5 \mathrm{~mm}$ were prepared for $45^{\circ}$ bevel welding, without a threshold and with a distance of $2 \mathrm{~mm}$. The welding source for the STT ${ }^{\circledR}$ process was a device from Lincoln Electric. The STT ${ }^{\circledR}$ power source marked INVERTEC ${ }^{\circledR}$ STT ${ }^{\circledR}$ II was equipped with a dedicated 4-roll wire feeder LF-33. The classic GMAW process was made using the Lincoln Electric PowerWave S350 source equipped with the LF-42 feeder. For making joints, a solid wire LNM 304LSi (Lincoln Electric) with a diameter of $1 \mathrm{~mm}$ was used for both welding methods. Each time, the gas shield was a gas mixture $\left(97.5 \% \mathrm{Ar}+2.5 \% \mathrm{CO}_{2}\right)$. The welding process was carried out in the PG position, from top to bottom. The plate labeled as 1 was welded with the STT ${ }^{\circledR}$ method using one bead. It turned out that using this welding method, a single pass was enough to make a complete weld. Plate 2 was made using the GMAW method also using single-bead welding. In this case, however, a complete filling of the welding groove was not obtained. For this reason, it was decided in the case of plate 3 for GMAW welding with 2 beads. In this case a full filling of the welding groove was obtained. Welding parameters are shown in tables 1 and 2.

Tab. 1: Parameters of welding with STT® method.

\begin{tabular}{cccccccc}
\hline $\begin{array}{c}\text { No of the } \\
\text { sample }\end{array}$ & $\begin{array}{c}\text { Welding } \\
\text { sequence }\end{array}$ & $\begin{array}{c}\text { Current } \\
(\mathrm{A})\end{array}$ & $\begin{array}{c}\text { Voltage } \\
(\mathrm{V})\end{array}$ & $\begin{array}{c}\text { Time of } \\
\text { welding } \\
(\mathrm{s})\end{array}$ & $\begin{array}{c}\text { Speed of } \\
\text { welding } \\
(\mathrm{mm} / \mathrm{s})\end{array}$ & $\begin{array}{c}\text { Background } \\
\text { Current (A) }\end{array}$ & $\begin{array}{c}\text { Peak } \\
\text { Current } \\
(\mathrm{A})\end{array}$ \\
\hline $\mathbf{1}$ & single pass & 109 & 15 & 122 & 2.46 & 61 & 231 \\
\hline
\end{tabular}

Tab. 2: Parameters of welding with GMAW method.

\begin{tabular}{cccccc}
\hline $\begin{array}{c}\text { No of the } \\
\text { sample }\end{array}$ & Welding sequence & $\begin{array}{c}\text { Current } \\
(\mathrm{A})\end{array}$ & $\begin{array}{c}\text { Voltage } \\
(\mathrm{V})\end{array}$ & $\begin{array}{c}\text { Time of } \\
\text { welding } \\
(\mathrm{s})\end{array}$ & $\begin{array}{c}\text { Speed of } \\
\text { welding } \\
(\mathrm{mm} / \mathrm{s})\end{array}$ \\
\hline $\mathbf{2}$ & single pass & 95 & 15 & 122 & 2.46 \\
\hline $\mathbf{3}$ & first pass & 95 & 15 & 123 & 2.44 \\
\cline { 2 - 6 } & second pass & 120 & 17.5 & 68 & 4.41 \\
\hline
\end{tabular}

\section{Results and analysis}

The joint on plate No. 1 made by the STT ${ }^{\circledR}$ method is characterized by very good aesthetics (Fig. 1a and 1d). A face and ridge were obtained with a very small protuberance, free from underflows. No spatter or other surface defects, which means that the quality of the weld joint certainly meets the highest level of quality B in accordance with the PN-EN ISO 5817 standard. Attempting to make a complete weld with one pass proved to be impossible to perform using the classical GMAW method. At the longer joint length (for L > $200 \mathrm{~mm}$ ), the groove on the face side was not filled completely, in some places the difference in height between the surface of the plate and the resulting weld reached $2 \mathrm{~mm}$ (Fig. 1e). In places where the weld metal is flush with the edge of the groove, no remelting of these edges was found. The third board made with the classic GMAW proved to be with a large number of welding imperfections. A convex face (reaching up to $2 \mathrm{~mm}$ in height) was obtained, and the second bead resulted in numerous spatter that were difficult to remove (Fig 1b). The spatter depending on the requirements for 
the quality of the welded surfaces can be the basis for questioning the quality of the final element with such defects. Visual tests showed incomplete root penetration (Fig. 1c). As a result, there are four places on the root with no penetration, which means that we have a disadvantage disqualifying the joint.

Figure 2a shows the structure of the base material, $\mathrm{X} 2 \mathrm{CrNi18}-9$ stainless steel. It is an austenitic structure with a small amount of $\delta$ ferrite. The structure of the heat affected zone (HAZ) made by the STT® method (Figure $2 b$ ) is characterized by a slight increase in austenite grain size near the fusion line and a slight increase in the amount of ferrite $\delta$ to about $20 \mu \mathrm{m}$ from the fusion line. In the case of samples welded with the GMAW method at one pass as well as two passes (Fig. 2c and 2d), an increase in the amount of ferrite $\delta$ near the fusion line is visible. The grain size remained in each of the analyzed cases at a similar level and did not differ much from the grain size in the base material.
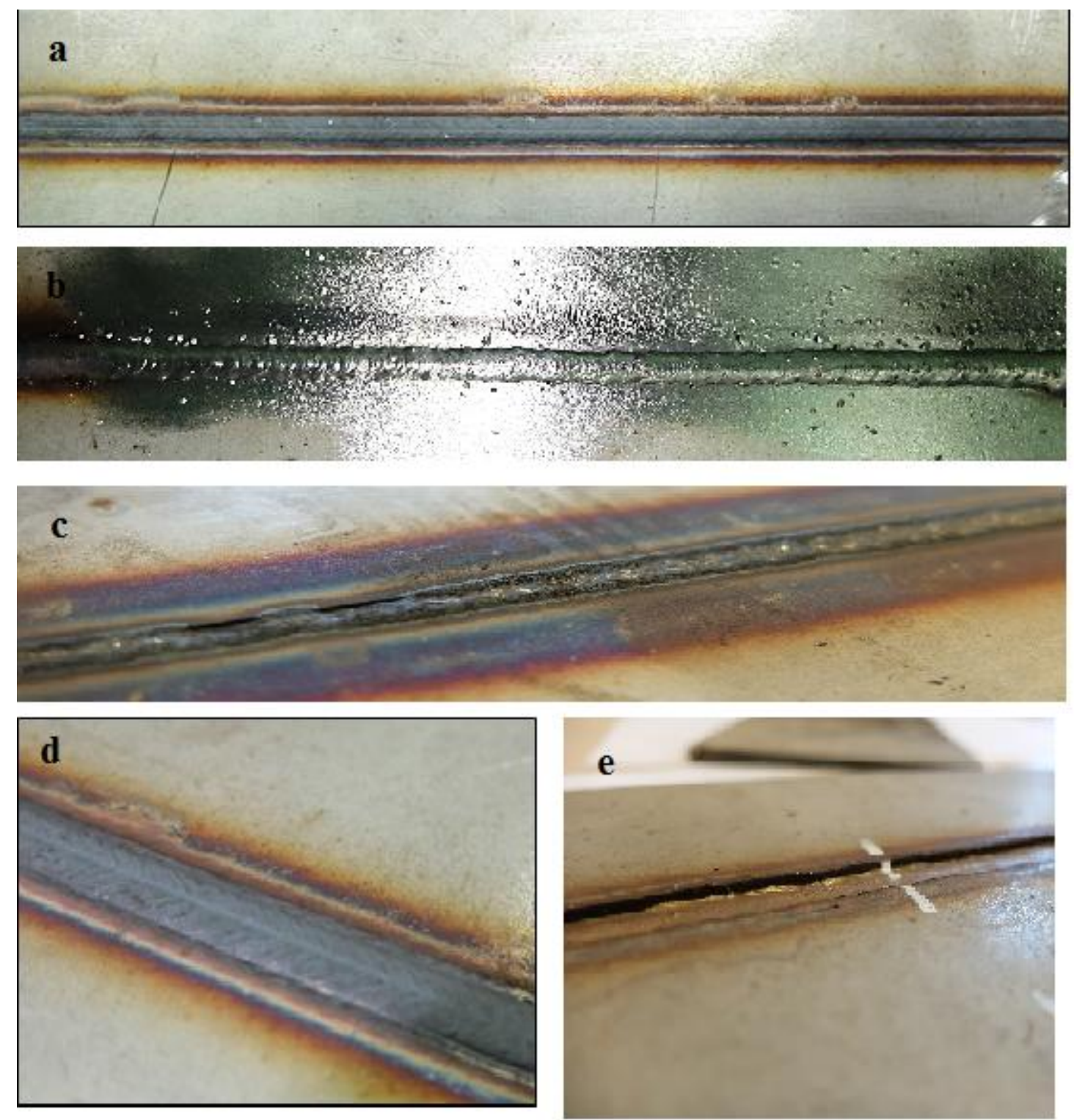

Fig. 1: View of welded joints made. Pictures (a) and (d) show the view of sample face made with $S T T{ }^{\circledR}$. Pictures (b) and (c) show a view of the face and root for sample number 3. Picture (e) shows the view of sample 2. 

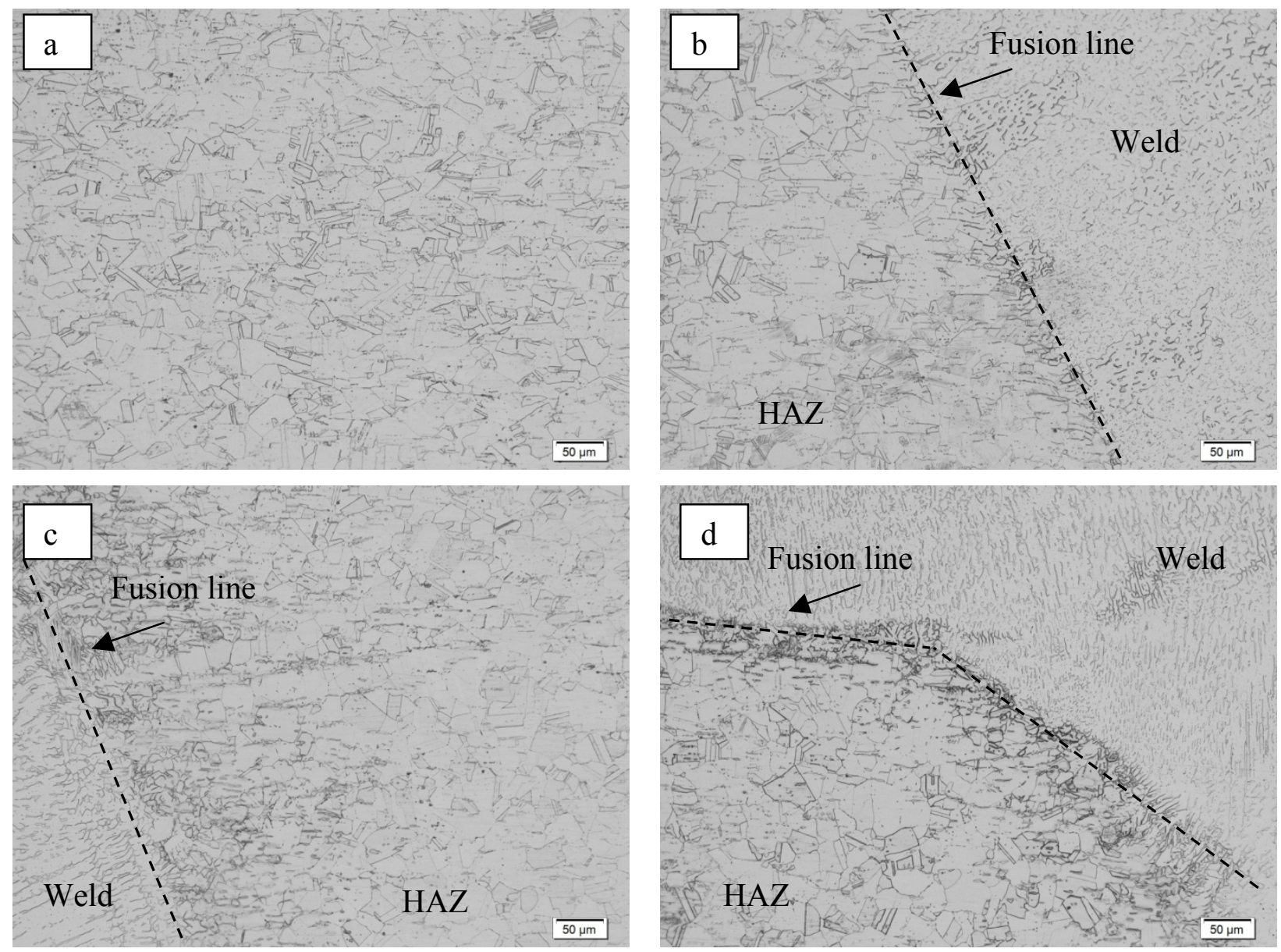

Fig. 2: The structure of the welded joint. Figure (a) is the structure of the base material, (b) structure after welding by the STT method, (c) structure after GMAW welding with one pass, (d) structure after GMAW welding with two passes.

\section{Conclusions}

The tests have shown that the use of the STT method for welding austenitic steel sheets gives much better results than the conventional GMAW method. The joints made by the STT method were free from splashes and it was possible to correctly make the joint at a single stitch position from top to bottom. The classical GMAW method during welding in this position was characterized by numerous lack of penetration and in the case of two-stroke welding with numerous splashes. Using the STT method, it is possible to limit the joint execution time and reduce the amount of ferrite $\delta$ in the structure near the fusion line. This can have a positive effect on the corrosion resistance of the entire joint.

\section{References}

Gucwa, M., Bęczkowski R., Grzyb A. (2014) Analysis of the content of $\delta$ ferrite in pulse-arc welded steel 304. Archivess of Foundry Engineering, 14, 1, pp. 131-134.

Mohammed R., Reddy G.M., Rao K.S. (2015) Microstructure and pitting corrosion of shielded metal arc welded high nitrogen stainless steel. Defence Technology,11, pp. 237-243.

Norrish, J. and Cuiuri, D. (2014) The controlled short circuit GMAW process: A tutorial. Journal of Manufacturing Processes, 16, pp. 86-92.

Scotti, A., Ponomarev, V., William Lucas, W. (2012) A scientific application oriented classification for metal transfer modes in GMA welding. Journal of Materials Processing Technology, 212, pp 1406-1413. 